\title{
Successful use of noninvasive ventilation in pregnancy
}

\author{
To the Editor:
}

Acute respiratory failure (ARF) occurs in less than $0.1 \%$ of pregnancies; however, it is one of the most common reasons for obstetric admissions to the intensive care unit (ICU) and carries a high mortality for both mother and fetus. Pulmonary physiological and anatomic adaptations during pregnancy affect the overall management, as well as predispose patients to complications during respiratory illness. Pregnancyrelated upper airway mucosal oedema may obstruct visualisation of the airway during intubation and can make invasive airway management difficult. The pregnant female requiring endotracheal intubation has a four-fold higher risk of having a difficult airway and an eight-fold higher risk of a failed intubation [1].

The application of noninvasive ventilation (NIV) in the treatment of ARF continues to expand as its benefits are increasingly recognised. NIV is often avoided in pregnancy due to the theoretical risk of aspiration. However, our current knowledge regarding the safety and efficacy of NIV for the management of respiratory failure in pregnancy is based on weak evidence. Only a few case reports and small case series have been published. Given the limited data, we review the current literature and report two cases of pregnant females who developed ARF from acute respiratory distress syndrome (ARDS) and were successfully and safely managed with NIV.

\section{Case 1}

A 30-year-old gravida 2 para 1 with an uncomplicated twin pregnancy presented with premature rupture of membranes at 30 weeks of gestation. She had also complained of a dry cough for 1 week prior to presentation and a low grade fever. Corticosteroids, antibiotics and tocolytic therapy were administered. On day 2 of admission, she developed acute shortness of breath and complained of severe chest pressure and worsening cough. Her oxygen saturation was $87 \%$ while breathing room air. On physical examination, she appeared to be in moderate respiratory distress, was alert and awake, and had reduced breath sounds bilaterally. Rhonchi were auscultated over her right lung field and she was subsequently transferred to the medical ICU.

Arterial blood gas (ABG) results on $100 \%$ oxygen via a non-rebreather mask showed an oxygen tension $\left(\mathrm{PO}_{2}\right)$ of $58 \mathrm{mmHg}$, pH of 7.49 and a carbon dioxide tension $\left(\mathrm{PCO}_{2}\right)$ of $27 \mathrm{mmHg}$. Her breathing became more laboured and the decision was made to place her on NIV with an inspiratory pressure of $12 \mathrm{cmH}_{2} \mathrm{O}$ and an expiratory pressure of $5 \mathrm{cmH}_{2} \mathrm{O}$. Inspiratory oxygen fraction $\left(\mathrm{FIO}_{2}\right)$ was set to $100 \%$. Fetal monitoring was initiated. Her work of breathing and oxygenation rapidly improved. Repeat ABG analysis $1 \mathrm{~h}$ later revealed a $\mathrm{PO}_{2}$ of $152 \mathrm{mmHg}$ on the same settings. Clindamycin was added for suspected aspiration pneumonia. Computed tomography of the chest showed diffuse, bilateral airspace disease. An echocardiogram was unremarkable. Over the next 2 days she was weaned off NIV and her clinical condition continued to improve. She tolerated the mask well and no episodes of aspiration or other complications occurred. However, her contractions were difficult to control and she delivered twins through caesarean section under regional anaesthesia. The delivery was uncomplicated and she was discharged home on oral antibiotics. Both infants did well and were released from the neonatal ICU several weeks later.

\section{Case 2}

A 24-year-old primigravida at 28 weeks of gestation was admitted for premature rupture of membranes and chorioamniotic separation. Similar to the previous case, she received tocolytics, antibiotics and steroids. Several hours after admission, she complained of new-onset shortness of breath with an oxygen saturation of $88 \%$ on room air. She was afebrile. On physical examination she was toxic appearing and anxious, but alert and responding appropriately. She was tachypnoeic and coarse rales were heard bilaterally. ABG measurements while on 50\% oxygen via a face mask were $\mathrm{PO}_{2} 79 \mathrm{mmHg}, \mathrm{PCO}_{2} 28 \mathrm{mmHg}$ and pH 7.47.

She was transferred to the medical ICU where NIV was initiated with the following settings: inspiratory pressure $12 \mathrm{cmH}_{2} \mathrm{O}$, expiratory pressure $8 \mathrm{cmH}_{2} \mathrm{O}$ and $\mathrm{FIO}_{2} 100 \%$. On NIV she appeared more comfortable and her oxygen saturation was $>95 \%$. Computed tomography of the chest was also performed and revealed diffuse ground-glass infiltrates consistent with pulmonary oedema along with bilateral lower lobe dense 
consolidations. An echocardiogram showed a normal ejection fraction. She was started on ampicillin, erythromycin and clindamycin for presumed pneumonia. During the next 3 days her respiratory status continued to improve and she was weaned off NIV, eventually requiring only nasal cannula. No adverse events were reported from NIV use. She underwent vaginal delivery of a preterm girl $48 \mathrm{~h}$ later without complication.

\section{Previous case reports of NIV use in pregnancy}

Several case reports and small series have shown favourable outcomes with NIV use for respiratory failure in pregnancy (table 1) [2-19].

The first investigations were mainly conducted in patients suffering from chronic ventilatory failure associated with severe kyphoscoliosis and neuromuscular diseases [2, 3]. BACH [2] described the successful use of NIV in four full-term pregnant females. Three females had chronic NIV-dependent respiratory failure due to prior poliomyelitis and one female developed ventilatory insufficiency due to severe kyphoscoliosis. With the assistance of NIV, all four females delivered healthy, full-term babies [2]. Further descriptions of NIV use in neuromuscular disease include two cases of successful pregnancies in females with chronic ventilatory insufficiency due to mitochondrial myopathy $[4,5]$.

NIV in pregnancy for indications other than ventilatory failure have also been described. Several studies demonstrating favourable outcomes with NIV use in parturients with hypoxaemic respiratory failure have been performed. The aetiologies range from pulmonary oedema associated with tocolytic agents to severe preeclampsia to aspiration pneumonia [6-8]. Surprisingly, several accounts of successful applications of NIV in pregnancy have also been described in ARDS. Cases of ARDS associated with all-trans-retinoic acid syndrome, community-acquired pneumonia, sepsis and, more recently, influenza A (H1N1) virus have been published previously [9-11]. AL-ANSARI et al. [12] described four pregnant patients with sickle cell disease who presented with acute chest syndrome and ARDS. All were successfully treated with NIV and endotracheal intubation was avoided. There were no episodes of aspiration [12].

More recent descriptions of NIV in pregnancy have shown favourable outcomes in unusual circumstances. Three reports have demonstrated perioperative use of NIV in combination with spinal anaesthesia for parturients with respiratory failure requiring emergency caesarean delivery [13-15]. A recent report also described the use of NIV with dexmedetomidine for sedation in a pregnant female with hypoxaemic respiratory failure from severe aspiration pneumonia [8].

It is important to emphasise the potential danger of using NIV in the setting of ARF in pregnancy, particularly in inexperienced hands. Patient selection is paramount and indications and contraindications to its use must be considered carefully. To optimise the safety of NIV in this setting, staff should be

TABLE 1 Summary of noninvasive ventilation experience in pregnancy

\begin{tabular}{|c|c|c|c|c|}
\hline First author [ref.] & Year & Design & Patients $\mathrm{n}$ & Aetiology of respiratory failure \\
\hline KÄHLER [3] & 2002 & Case report & 1 & Ventilatory failure, severe kyphoscoliosis \\
\hline BACH [2] & 2003 & Case series & 3 & Ventilatory failure, neuromuscular (severe poliomyelitis ${ }^{\#}$ ) \\
\hline Díaz-Lobato [4] & 2005 & Case series & 2 & Ventilatory failure, neuromuscular (mitochondrial myopathy) \\
\hline REDDY [16] & 2005 & Case report & 1 & Ventilatory failure, severe kyphoscoliosis \\
\hline TERAJIMA [15] & 2006 & Case report & 1 & Non-cardiogenic pulmonary oedema \\
\hline AL-ANSARI [12] & 2007 & Case series & 4 & ARDS, acute chest syndrome \\
\hline BASSANI [10] & 2009 & Case report & 1 & ARDS/ATRA syndrome \\
\hline YUAN [5] & 2009 & Case report & 1 & Ventilatory failure, neuromuscular (mitochondrial myopathy) \\
\hline GUTERRES [14] & 2010 & Case report & 1 & Ventilatory failure, neuromuscular (high neuraxial blockade) \\
\hline DJIBRÉ [11] & 2010 & Case report & 1 & ARDS, H1N1 \\
\hline ERDOGAN [13] & 2010 & Case report & 1 & Non-cardiogenic pulmonary oedema, severe preeclampsia \\
\hline FRASSANITO [17] & 2011 & Case report & 1 & ARDS, sepsis \\
\hline
\end{tabular}

ARDS: acute respiratory distress syndrome; ATRA: all-trans-retinoic acid; H1N1: influenza A virus infection. ${ }^{\#}$ : pregnancies in home ventilator users. 
experienced in its use and patients should be in a protected environment, such as an ICU, in order to monitor changes in the clinical state of the mother and fetus.

In conclusion, little is known about the safety and efficacy of NIV for the management of respiratory failure in pregnancy. However, its use in this population shows promise as demonstrated by favourable outcomes in existing case reports and case series, including the two cases presented here. Given the paucity of published data, this small series is an important contribution to the literature. In carefully selected and closely monitored pregnant patients, NIV may be considered as a reasonable and safe option for the management of ARF. However, a large prospective trial to confirm these findings is warranted.

○ @ERSpublications

Noninvasive ventilation may be safe and effective for treating acute respiratory failure in pregnant patients http://ow.ly/sxlkU

Charles C. Allred ${ }^{1}$, Antonio Matías Esquinas ${ }^{2}$, Jonathan Caronia ${ }^{1}$, Ramyar Mahdavi ${ }^{1}$ and Bushra A. Mina ${ }^{1}$

${ }^{1}$ Dept of Medicine, Division of Pulmonary and Critical Care Medicine, Lenox Hill Hospital, New York, NY, USA.

${ }^{2}$ Intensive Care Unit, Hospital Morales Meseguer, Murcia, Spain.

Correspondence: C.C. Allred, Dept of Medicine, Division of Pulmonary and Critical Care Medicine, Lenox Hill Hospital, 100 East 77th Street, New York, NY 10075, USA. E-mail: charliecallred@gmail.com

Received: Nov 242013 | Accepted after revision: Dec 192013

Conflict of interest: None declared.

Provenance: Submitted article, peer reviewed.

\section{References}

Mighty HE. Acute respiratory failure in pregnancy. Clin Obstet Gynecol 2010; 53: 360-368.

Bach JR. Successful pregnancies for ventilator users. Am J Phys Med Rehabil 2003; 82: 226-229.

Kähler CM, Högl B, Habeler R, et al. Management of respiratory deterioration in a pregnant patient with severe kyphoscoliosis by non-invasive positive pressure ventilation. Wien Klin Wochenschr 2002; 114: 874-877.

4 Díaz-Lobato S, Gómez Mendieta MA, Moreno García MS, et al. Two full-term pregnancies in a patient with mitochondrial myopathy and chronic ventilatory insufficiency. Respiration 2005; 72: 654-656.

5 Yuan N, El-Sayed YY, Ruoss SJ, et al. Successful pregnancy and cesarean delivery via noninvasive ventilation in mitochondrial myopathy. J Perinatol 2009; 29: 166-167.

6 Perbet S, Constantin JM, Bolandard F, et al. Ventilation non-invasive pour œedème pulmonaire attribue aux tocolytiques lors du travail d'une grossesse gémellaire [Non-invasive ventilation for pulmonary edema associated with tocolytic agents during labour for a twin pregnancy]. Can J Anaesth 2008; 55: 769-773.

7 Rojas-Suarez J, Cogollo-González M, García-Rodríguez MC, et al. Ventilación mecánica no invasiva como estrategia adyuvante en el manejo del fallo respiratorio agudo secundario a edema pulmonar periparto por preeclampsia severa [Non-invasive mechanical ventilation as adjuvant strategy in the management of acute respiratory failure secondary to peripartum pulmonary edema in severe preeclampsia]. Med Intensiva 2011; 35: 518-519.

8 Duan M, Lee J, Bittner EA. Dexmedetomidine for sedation in the parturient with respiratory failure requiring noninvasive ventilation. Respir Care 2012; 57: 1967-1969.

9 Banga A, Khilnani GC. Use of non-invasive ventilation in a pregnant woman with acute respiratory distress syndrome due to pneumonia. Indian J Chest Dis Allied Sci 2009; 51: 115-117.

10 Bassani MA, de Oliveira AB, Oliveira Neto AF. Noninvasive ventilation in a pregnant patient with respiratory failure from all-trans-retinoic-acid (ATRA) syndrome. Respir Care 2009; 54: 969-972.

11 Djibré M, Berkane N, Salengro A, et al. Non-invasive management of acute respiratory distress syndrome related to Influenza A (H1N1) virus pneumonia in a pregnant woman. Intensive Care Med 2010; 36: 373-374.

12 Al-Ansari MA, Hameed AA, Al-jawder SE, et al. Use of noninvasive positive pressure ventilation during pregnancy: case series. Ann Thorac Med 2007; 2: 23-25.

13 Erdogan G, Okyay DZ, Yurtlu S, et al. Non-invasive mechanical ventilation with spinal anesthesia for cesarean delivery. Int J Obstet Anesth 2010; 19: 438-440.

14 Guterres AP, Newman MJ. Total spinal following labour epidural analgesia managed with non-invasive ventilation. Anaesth Intensive Care 2010; 38: 373-375.

15 Terajima K, Suzuki R, Suganuma R, et al. Non-invasive positive pressure ventilation and subarachnoidal blockade for Caesarean section in a parturient with pulmonary oedema. Acta Anaesthesiol Scand 2006; 50: 1307-1308.

16 Reddy R, Evans E, Khoo O, et al. Pregnancy in kyphoscoliosis: benefit of non-invasive ventilatory support. J Obstet Gynaecol 2005; 25: 267-268.

17 Frassanito L, Draisci G, Pinto R, et al. Successful application of helmet non-invasive ventilation in a parturient with acute respiratory distress syndrome. Minerva Anestesiol 2011; 77: 1121-1123.

18 Dalar L, Caner H, Eryuksel E, et al. Application of non-invasive mechanical ventilation in an asthmatic pregnant woman in respiratory failure: a case report. J Thorac Dis 2013; 5: 97-100.

19 Draisci G, Volpe C, Pitoni S, et al. Non-invasive ventilation for acute respiratory failure in preterm pregnancy. Int $J$ Obstet Anesth 2013; 22: 169-171. 